Vietnam Journal of Mechanics, NCST of Vietnam Vol. 25, 2003, No 3 (97-112)

\title{
APPLYING THE CONTACT ELEMENT FOR SIMULATION OF INTERACTION BETWEEN DRILLSTRING AND HOLEWALL
}

\author{
Le Phuoc Hao, Ta Quoc Dung \\ Drilling and Production Department, Faculty of Geology and Petroleum \\ Ho Chi Minh City University of Technology
}

\begin{abstract}
The purpose of research is to create a contact element in order to simulate the dynamics contact phenomenon of drillstring and drillhole. The contact element is located at some selected node along the drillstring. In the contact element, not only transverse friction force but also the longitudinal friction forces are taken into account. The element stiffness and damping matrices are derived explicitly. This element is implemented in general and powerful multi-body dynamics analysis software, namely Mecano module of Samcef. Therefore, many computational aspects of the Mecano software, for example the nonlinear beam element, the implicit time integration method, can be directly applied.
\end{abstract}

\section{Introduction}

The equipment for oil well drilling consists basically of five distinct subsystems: hoisting, circulating, rotating components, well control and power system. These five subsystems make a complete drilling system which is located over a wellhead for the sole purpose of making a hole in the ground. Among the five subsystems, the rotating components, or drillstring system, play an important role during drilling. The main purpose of this paper is to research a contact element for the simulation when drillstring contacts to holewall. The contact element is located at some selected node along the drillstring. If the contact at one node occurs, the contact element at this node is introduced. In this way, all the contact points along the drillstring can be determined.

The contact force analysis can be used for two purposes:

* To study the mechanical behavior of the bottom hole assembly (BHA), such as the position of the BHA in the wellbore, contact forces, and mechanical stresses in the borehole (Fig. 1). This information is useful for studying tool failure, stabilizer wear, and stuck pipe problems.

* To predict neutral point of drillstring.

\section{Contact element for BHA dynamic analysis}

\subsection{Composition of structure}

The BHA used for the drilling of oil and gas wells is often made up of different sizes of drill collars, stabilizers and downhole tools. It is usually subject to large 
axial compression force (WOB). The main purpose of drill collars is to apply force to the drill bit for penetration. Compression developed within drill collar causes the to buckle inside the wellbore and this creates side loads on the bit. So, it is necessary to use stabilizer to control the direction of the borehole and to increase the buckling stability.

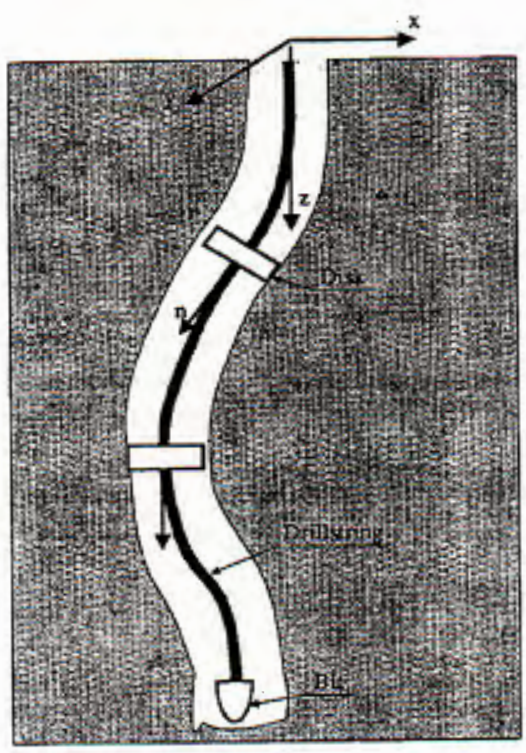

Fig. 1. Drillstring and the drilled hole

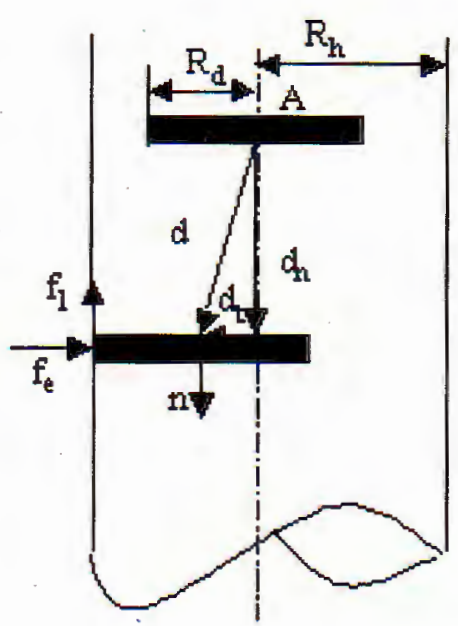

Fig. 2. Model of disk-holewall contact

In order to simulate the contact between drillstring and holewall, two essential issues are important. The first issue is how to determine the contact point along the drillstring at a given time. The second issue is how to introduce the contact law after the contact occurs, such as friction force evaluation, contact stiffness.

\subsection{Assumption}

In summary, the following assumptions are made for the sake of simplicity without loss of the main characteristics:

- Only stabilizer and holewall are taken into account. The other possible contacts between drill collar and holewall, bit-holewall are all disregarded.

- The stabilizer is assumed as a rigid supporter for simplicity.

- The contact element is infinitely rigid without mass (stabilizer).

- The cross section of the hole in the disk plane is circular.

- The disk is rotating around its normal vector $\mathbf{n}$ with a constant speed $\omega$.

Consider Fig. 2 with two coordinate systems. The global coordinate system, $x y z$, is fixed in the space. The movement of the drillstring is expressed in terms of this Cartesian coordinate. The hole geometry may be determined according to the initial position of the drillstring. In other words, the tangent of the initial curvature of the 

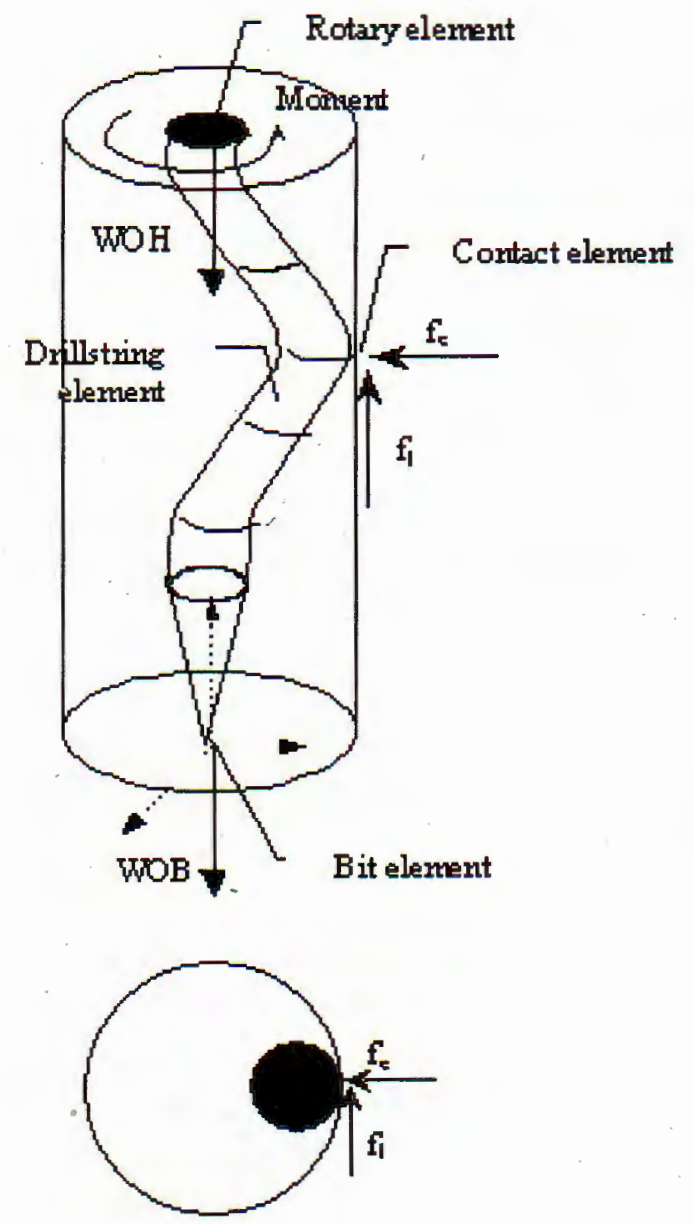

Fig. 3. Drillstring model drillstring is a good representation of the hole curve itself. This assumption is reasonable because the hole is drilled by the movement of the drillstring. The second coordinate system is a local coordinate frame which is represented by the disk normal direction $n$ at the disk center. The initial coordinate of the disk center, $x_{0} y_{0} z_{0}$, is the reference point of this contact element. It is assumed that the normal disk vector $\mathbf{n}$ has the same direction as the tangent direction of the reference point and does not change during the vibration simulation. It is also assumed that the contact occurs only in the disk plane (reference plane).

Fig. 3 sketches a drillstring-holewall and kinematic variable which are necessary for the computation of contact force when drillstring vibrates.

\subsection{Contact condition}

Let us consider the local coordinate at the contact point (Fig. 2). At time t, the reference point moves from $A\left(x_{0}, y_{0}, z_{0}\right)$ to $B(x, y, z)$. Therefore, the element displacement is:

$$
\mathbf{d}=\left(\begin{array}{lll}
x-x_{0} & y-y_{0} & z-z_{0}
\end{array}\right)^{T}
$$

The projection of the displacement vector $\mathbf{d}$ on the vector $\mathbf{n}$ is given by:

$$
\mathbf{d}_{n}=(\mathbf{d} \cdot \mathbf{n}) \mathbf{n}=\left(\begin{array}{l}
\left(x-x_{0}\right) n_{1}^{2}+\left(y-y_{0}\right) n_{1} n_{2}+\left(z-z_{0}\right) n_{1} n_{3} \\
\left(x-x_{0}\right) n_{1} n_{2}+\left(y-y_{0}\right) n_{2}^{2}+\left(z-z_{0}\right) n_{2} n_{3} \\
\left(x-x_{0}\right) n_{1} n_{3}+\left(y-y_{0}\right) n_{2} n_{3}+\left(z-z_{0}\right) n_{3}^{2}
\end{array}\right)
$$

where $\mathbf{n}=\left(\begin{array}{lll}n_{1} & n_{2} & n_{3}\end{array}\right)^{T}$.

The transversal displacement $\mathbf{d}_{t}$ is then:

$$
\mathbf{d}_{t}=\mathbf{d}-\mathbf{d}_{n}=\left(\begin{array}{c}
\left(x-x_{0}\right)\left(1-n_{1}\right)^{2}-\left(y-y_{0}\right) n_{1} n_{2}-\left(z-z_{0}\right) n_{1} n_{3} \\
-\left(x-x_{0}\right) n_{1} n_{2}+\left(y-y_{0}\right)\left(1-n_{2}^{2}\right)+\left(z-z_{0}\right) n_{2} n_{3} \\
-\left(x-x_{0}\right) n_{1} n_{3}+\left(y-y_{0}\right) n_{2} n_{3}+\left(z-z_{0}\right)\left(1-n_{3}^{2}\right)
\end{array}\right)
$$


If the module $\left|\mathrm{d}_{t}\right|$ is greater than the clearance $\Delta R=R_{h}-R_{d}$, i.e., if

$$
\left|\mathrm{d}_{t}\right|-\Delta R>0
$$

then there is a contact between the disk and the holewall.

The unit vector of $d_{t}$ may be determined by:

$$
\mathbf{u}=\frac{\mathbf{d}_{t}}{\left|\mathbf{d}_{t}\right|}=\left(\begin{array}{l}
u_{1} \\
u_{2} \\
u_{3}
\end{array}\right)
$$

The unit vector $\mathbf{u}$ represents the contact direction. In the following sections, it will be shown that the unit vectors $\mathbf{u}$ and $\mathbf{n}$ are the two basic vectors for determination of the contact forces.

\subsection{Forces induced by contact}

As shown in Fig. 2, the contact between the massless disk and the holewall will generate four forces, i.e., elastic force, damping force, transversal friction force and longitudinal friction force. They are expressed below.

\subsubsection{Elastic force}

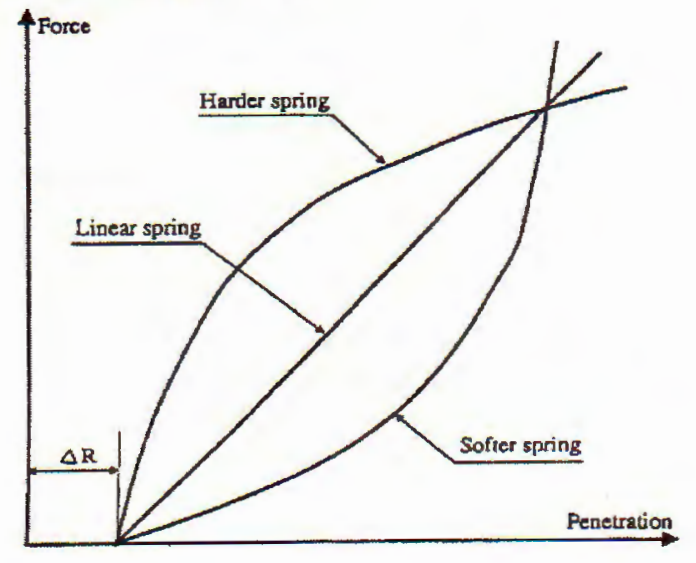

Fig. 4. Elastic force models

The elastic forces or the restoring forces induced by the contact between the disk and the holewall are due to the elasticity of the holewall. Shown in Fig. 4 are three kinds of models for the elastic forces, i.e., the linear spring model, the hard spring model and the soft spring model.

For displacement below the deadband threshold, the elastic force is zero. Mathematically, the modulus of the elastic force can be described by

$$
f_{e}= \begin{cases}k_{e}\left(\left|d_{t}\right|-\Delta R\right)^{m}, & \text { if contact occurs } \\ 0, & \text { otherwise }\end{cases}
$$

where $k_{e}$ is the stiffness of the holewall at contact point and $\Delta R$ is the clearance between the disk and the holewall. The value of $m$ is:

$$
m= \begin{cases}1, & \text { linear spring model; } \\ >1, & \text { hard spring model (usually } m=3 / 2 \text { ) } \\ <1, & \text { soft spring model (usually } m=2 / 3 \text { ) }\end{cases}
$$


The direction of $f_{e}$ is shown in Fig. 2. Therefore, the elastic force vector is:

$$
f_{e}=f_{e} u=\left(\begin{array}{l}
f_{e} u_{1} \\
f_{e} u_{2} \\
f_{e} u_{3}
\end{array}\right)
$$

\subsubsection{Damping force}

The damping force modulus is:

$$
f_{d}=C v_{t}
$$

where $v_{t}$ is the modulus of the disk velocity. in the contact direction. If $\mathbf{v}$ is the velocity vector of the disk center, $v_{t}$ can be written:

$$
v_{t}=\mathbf{v} \cdot \mathbf{u}=v_{1} u_{1}+v_{2} u_{2}+v_{3} u_{3}
$$

where $\mathbf{v}=\left(\begin{array}{lll}v_{1} & v_{2} & v_{3}\end{array}\right)^{T}$

The damping force vector is then:

$$
\mathbf{f}_{d}=f_{d} \mathbf{u}=\left(\begin{array}{l}
f_{d} u_{1} \\
f_{d} u_{2} \\
f_{d} u_{3}
\end{array}\right)
$$

\subsubsection{Transverse friction force and moment}

The modulus of the transverse friction force is:

$$
f_{t}=\mu_{t}\left(f_{e}+f_{d}\right) .
$$

This force lies in the disk plane. In order to define its direction, however, two cases have to be considered:

Case 1: Static analysis

In this case, the direction of the transverse friction force can be determined by the disk rotation:

$$
\mathbf{f}_{t}=f_{t}(\mathbf{u} \times \mathbf{n})
$$

It is noted that the disk rotating vector $\omega$ coincides with the vector $\mathbf{n}$.

Case 2: Dynamic analysis

In the case of dynamic analysis, the disk rotates around its center; meanwhile, the disk center vibrates. It means that the contact velocity at the contact point includes two terms: (1) the term $\mathbf{v}^{t \omega}$ induced by disk rotation $\omega$ and (2) the term $\mathbf{v}^{t t}$ induced by the vibration of the disk center. These two terms can be evaluated respectively as follows:

$$
\begin{aligned}
\mathbf{v}^{t \omega} & =R_{d}(u \times \omega) \\
\mathbf{v}^{t t} & =\mathbf{v}-(\mathbf{v} \cdot \mathbf{u}) \mathbf{u} .
\end{aligned}
$$


Therefore, the contact velocity is:

$$
\mathbf{v}^{t}=\mathbf{v}^{t \omega}+\mathbf{v}^{t t} .
$$

Finally, the transversal friction force vector in the dynamic case is:

$$
\mathbf{f}_{t}=-f_{t} \frac{\mathbf{v}^{t}}{\left|\mathbf{v}^{t}\right|} .
$$

In order to avoid the singularities in the computation, equation (2.17) is modified by

$$
\mathbf{f}_{t}= \begin{cases}-\mathbf{f}_{t} \frac{\mathbf{v}_{t}}{\left|\mathbf{v}^{t}\right|}, & \text { if }\left|\mathbf{v}^{t}\right| \geq \varepsilon \\ -\mathbf{f}_{t}\left(2-\frac{\mathbf{v}_{t}}{\varepsilon}\right) \frac{\mathbf{v}_{t}}{\varepsilon}, & \text { otherwise. }\end{cases}
$$

where $\varepsilon$ is a small value, usually equal to $10^{-3}$.

Because the friction force acts at the surface of the disk, it generates an additional friction moment. For both static and dynamic analysis, this additional friction moment is obtained by

$$
\mathbf{m}_{t}=R_{d}\left(\mathbf{u} \times \mathbf{f}_{t}\right)
$$

\subsubsection{Longitudinal friction force and moment}

The force modulus is:

$$
f_{l}=\mu_{t}\left(f_{e}+f_{d}\right)
$$

The longitudinal velocity at the contact point is:

$$
v_{1}=\mathbf{v} \cdot \mathbf{u}=v_{1} u_{1}+v_{2} u_{2}+v_{3} u_{3} .
$$

Therefore; the longitudinal friction force vector is:

$$
f_{l}=S_{l} f_{l n}
$$

where

$$
S_{l}=\operatorname{sign}\left(v_{l}\right)= \begin{cases}1, & \text { if } v_{1}<0 \\ 0, & \text { if } v_{1}=0 \\ -1, & \text { if } v_{1}>0\end{cases}
$$

In order to avoid the singularity of the derivative at $v_{l}=0$, equation $(2.22)$ is modified by

$$
S_{l}= \begin{cases}\frac{v_{l}}{\left|v_{l}\right|}, & \text { if }\left|v_{l}\right| \geq \varepsilon \\ \left(2-\frac{v_{l}}{\varepsilon}\right) \frac{v_{l}}{\varepsilon}, & \text { if }\left|v_{l}\right|<\varepsilon\end{cases}
$$


Like as the transversal friction force, the longitudinal force generates also an additional moment which can be given by

$$
\mathbf{m}_{l}=f_{l} S_{l} R_{l}(n \times u)=\left(\begin{array}{l}
f_{l} S_{l} R_{l}\left(n_{2} u_{3}-n_{3} u_{2}\right) \\
f_{l} S_{l} R_{l}\left(n_{3} u_{1}-n_{1} u_{3}\right) \\
f_{l} S_{l} R_{l}\left(n_{1} u_{2}-n_{2} u_{1}\right)
\end{array}\right)
$$

\subsection{Element matrices}

Because the disk is massless, only stiffness and damping matrices are needed for the contact element. The stiffness and the damping matrices are the sum of four terms, respectively:

$$
\begin{aligned}
K & =K_{e}+K_{d}+K_{f}^{t}+K_{f}^{l} \\
C & =C_{e}+C_{d}+C_{f}^{t}+C_{f}^{l}
\end{aligned}
$$

where $K_{e}, K_{d}, K_{f}^{t}, K_{f}^{l}$ are stiffness matrices corresponding to the elastic force, damping force, transverse friction force and longitudinal friction force, respectively. $C_{e}, C_{d}, C_{f}^{t}, C_{f}^{l}$ are damping matrices associated with these forces. These matrices are derived below.

2.5.1. $K_{e}$ and $C_{e}$

$$
\begin{aligned}
& K_{e}(i, j)=\frac{\partial\left(f_{e} u_{i}\right)}{\partial q_{j}}=\frac{\partial f_{e}}{\partial q_{j}} u_{i}+f_{e} \frac{\partial u_{i}}{\partial q_{j}}, \quad i, j=1,2,3 \\
& C_{e}(i, j)=\frac{\partial\left(f_{e} u_{i}\right)}{\partial \dot{q}_{j}}=0, \quad i, j=1,2,3 .
\end{aligned}
$$

2.5.2. $K_{d}$ and $C_{d}$

$$
\begin{aligned}
& K_{d}(i, j)=\frac{\partial\left(f_{d} u_{i}\right)}{\partial q_{j}}=\frac{\partial f_{d}}{\partial q_{j}} u_{i}+f_{d} \frac{\partial u_{i}}{\partial q_{j}}, \quad i, j=1,2,3 \\
& C_{d}(i, j)=\frac{\partial\left(f_{d} u_{i}\right)}{\partial \dot{q}_{j}}=c u_{i} u_{j}
\end{aligned}
$$

2.5.3. $K_{f}^{t}$ and $C_{f}^{t}$

Two cases are considered.

Case 1: Static analysis

In the static analysis, the internal force vector is:

$$
\mathbf{g}_{t}^{i n t}=\left(\begin{array}{c}
\mathbf{f}_{t} \\
\mathbf{m}_{t}
\end{array}\right)=\left(\begin{array}{c}
f_{t}\left(n_{3} u_{2}-n_{2} u_{3}\right) \\
f_{t}\left(n_{1} u_{3}-n_{3} u_{1}\right) \\
f_{t}\left(n_{2} u_{1}-n_{1} u_{2}\right) \\
f_{t} R_{d} n_{1} \\
f_{t} R_{d} n_{2} \\
f_{t} R_{d} n_{3}
\end{array}\right)
$$


the matrix $K_{f}^{t}$ and $C_{f}^{t}$ are obtained from:

$$
\begin{aligned}
K_{f}^{t}(1, j) & =\frac{\partial f_{t}}{\partial q_{j}}\left(n_{3} u_{2}-n_{2} u_{3}\right)+f_{t}\left(n_{3} \frac{\partial u_{2}}{\partial q_{j}}-n_{2} \frac{\partial u_{3}}{\partial q_{j}}\right) \\
K_{f}^{t}(2, j) & =\frac{\partial f_{t}}{\partial q_{j}}\left(n_{1} u_{3}-n_{3} u_{1}\right)+f_{t}\left(n_{1} \frac{\partial u_{3}}{\partial q_{j}}-n_{3} \frac{\partial u_{1}}{\partial q_{j}}\right) \\
K_{f}^{t}(3, j) & =\frac{\partial f_{t}}{\partial q_{j}}\left(n_{2} u_{1}-n_{1} u_{2}\right)+f_{t}\left(n_{2} \frac{\partial u_{1}}{\partial q_{j}}-n_{1} \frac{\partial u_{2}}{\partial q_{j}}\right) \\
K_{f}^{t}(i, j) & =R_{d} \frac{\partial f_{t}}{\partial q_{j}} n_{i}, \quad i=4 \sim 6, \\
C_{f}^{t}(1, j) & =\mu_{t} c u_{j}\left(n_{3} u_{2}-n_{2} u_{3}\right) \\
C_{f}^{t}(2, j) & =\mu_{t} c u_{j}\left(n_{1} u_{3}-n_{3} u_{1}\right) \\
C_{f}^{t}(3, j) & =\mu_{t} c u_{j}\left(n_{2} u_{1}-n_{1} u_{2}\right) \\
C_{f}^{t}(i, j) & =c \mu_{t} R_{d} u_{j} n_{i} ; \quad i=4,5,6 \quad j=1,2,3 .
\end{aligned}
$$

Case 2: Dynamic analysis

The internal force vector is:

$$
\mathbf{g}_{t}^{\text {int }}=\left(\begin{array}{c}
\mathbf{f}_{t} \\
\mathbf{m}_{t}
\end{array}\right)
$$

The stiffness matrix is:

$$
K_{f}^{t}(i, j)=\frac{\partial \mathbf{g}_{t}^{i n t}}{\partial \mathbf{q}_{j}}
$$

where $i=1 \sim 6, j=1 \sim 3$.

And the damping matrix is:

$$
C_{f}^{t}(i, j)=\frac{\partial \mathrm{g}_{t}^{i n t}}{\partial \dot{q}_{j}}
$$

where $i=1 \sim 6, j=1 \sim 3$.

2.5.4. $K_{f}^{l}$ and $C_{f}^{l}$

The internal force vector associated with the longitudinal friction force is obtained by combining the nodal force and moment:

$$
\mathbf{g}_{t}=\left(\begin{array}{c}
\mathbf{f}_{l} \\
\mathbf{m}_{l}
\end{array}\right)=\left(\begin{array}{c}
S_{l} f_{l} n_{1} \\
S_{l} f_{l} n_{2} \\
S_{l} f_{l} n_{3} \\
f_{l} S_{l} R_{d}\left(n_{2} u_{3}-n_{3} u_{2}\right) \\
f_{l} S_{l} R_{d}\left(n_{3} u_{1}-n_{1} u_{3}\right) \\
f_{l} S_{l} R_{d}\left(n_{1} u_{2}-n_{2} u_{1}\right)
\end{array}\right)
$$


The stiffness matrix is explicitly given by:

$$
\begin{aligned}
& K_{f}^{l}(i, j)=\frac{\partial f_{l}}{\partial q_{j}} n_{i} S_{l}, \quad i, j=1,2,3 \\
& K_{f}^{l}(4, j)=\frac{\partial f_{l}}{\partial q_{j}} R_{d} S_{l}\left(n_{2} u_{3}-n_{3} u_{2}\right)+f_{l} R_{d} S_{l}\left(n_{2} \frac{\partial u_{3}}{\partial q_{j}}-n_{3} \frac{\partial u_{2}}{\partial q_{j}}\right) \\
& K_{f}^{l}(5, j)=\frac{\partial f_{l}}{\partial q_{j}} R_{d} S_{l}\left(n_{3} u_{1}-n_{1} u_{3}\right)+f_{l} R_{d} S_{l}\left(n_{2} \frac{\partial u_{1}}{\partial q_{j}}-n_{3} \frac{\partial u_{3}}{\partial q_{j}}\right) \\
& K_{f}^{l}(6, j)=\frac{\partial f_{l}}{\partial q_{j}} R_{d} S_{l}\left(n_{1} u_{2}-n_{2} u_{1}\right)+f_{l} R_{d} S_{l}\left(n_{2} \frac{\partial u_{2}}{\partial q_{j}}-n_{3} \frac{\partial u_{1}}{\partial q_{j}}\right)
\end{aligned}
$$

The damping matrix is:

$$
\begin{aligned}
& C_{f}^{l}(i, j)=\mu_{l} c S_{l} u_{j} n_{i}, \quad i, j=1,3 \\
& C_{f}^{t}(4, j)=\mu_{t} c S_{l} u_{j} R_{d}\left(n_{2} u_{3}-n_{3} u_{2}\right) \\
& C_{f}^{t}(5, j)=\mu_{t} c S_{l} u_{j} R_{d}\left(n_{3} u_{1}-n_{1} u_{3}\right) \\
& C_{f}^{t}(6, j)=\mu_{t} c S_{l} u_{j} R_{d}\left(n_{1} u_{2}-n_{2} u_{1}\right)
\end{aligned}
$$

\section{Numerical application}

\subsection{Initial condition}

For a torque and drag problem, the drillstring is subjected the following boundary conditions:

- At the bit, the normal displacements $\left(U_{X}, U_{Y}\right)$ are zero, the axial applied force $\left(F_{Z}\right)$ is the downhole weight on bit (WOB), and the axial applied torque is the downhole torque on bit (TOB).

- At the surface (top of the drill string), a clamping condition of the drillstring to the rotary table is used (all displacements and all transverse rotations are zero, and the axial rotation versus the rotary table is zero).

- The drillstring is initially close to the steady state. Drilling is drilled at $1000 \mathrm{~m}$ depth. In this time, drillstring is continued drillpipe which is $20 \mathrm{~m}$ long. Circular velocity of drilltring increased from 0 to 120 rotation/minute in $50 \mathrm{~s}$.

\subsection{Input data}

The characteristics of drillstring are shown below

Table 1. Parameters of drillstring model

\begin{tabular}{lcll}
\hline Gravity of drillstring & 7890 & Radius out drillstring & 0.127 \\
Weight of bit (WOB) & $89 . \mathrm{E} 3$ & Radius in drillstring & 0.108 \\
Weight of hook (WHO) & $1.1 \mathrm{E} 6$ & Radius out collar & 0.165 \\
Friction factor & 0.4 & Radius in collar & 0.071
\end{tabular}




\begin{tabular}{lclc} 
Mud gravity & 1.2 & Radius of casing (hole wall): & 0.215 \\
RPM & 120 & Average stiffness of holewall & $6 . E 7$ \\
ROP & 24.5 & Average damping of formation & $8 . E 3$ \\
\hline
\end{tabular}

\subsection{Results analysis}

\subsubsection{Drillstring model with one stabilizer}

Drilling with one or two stabilizer, which refers to holding assemblies is used to drill straight section of the well. To this end, stabilizers are positioned within drill collars so those relatively small side forces are developed. Fig. 5 shows that there is a significant decrease of axial displacement at the beginning of simulation. It goes down from 0 at beginning to approximately $0.035 \mathrm{~m}$ at 10 second later. However, due to influences of damping at the bit, position of bit rises and fluctuates about $0.1 \mathrm{~m}$. It can be seen that impact of load at early time is main cause of significant displacement.

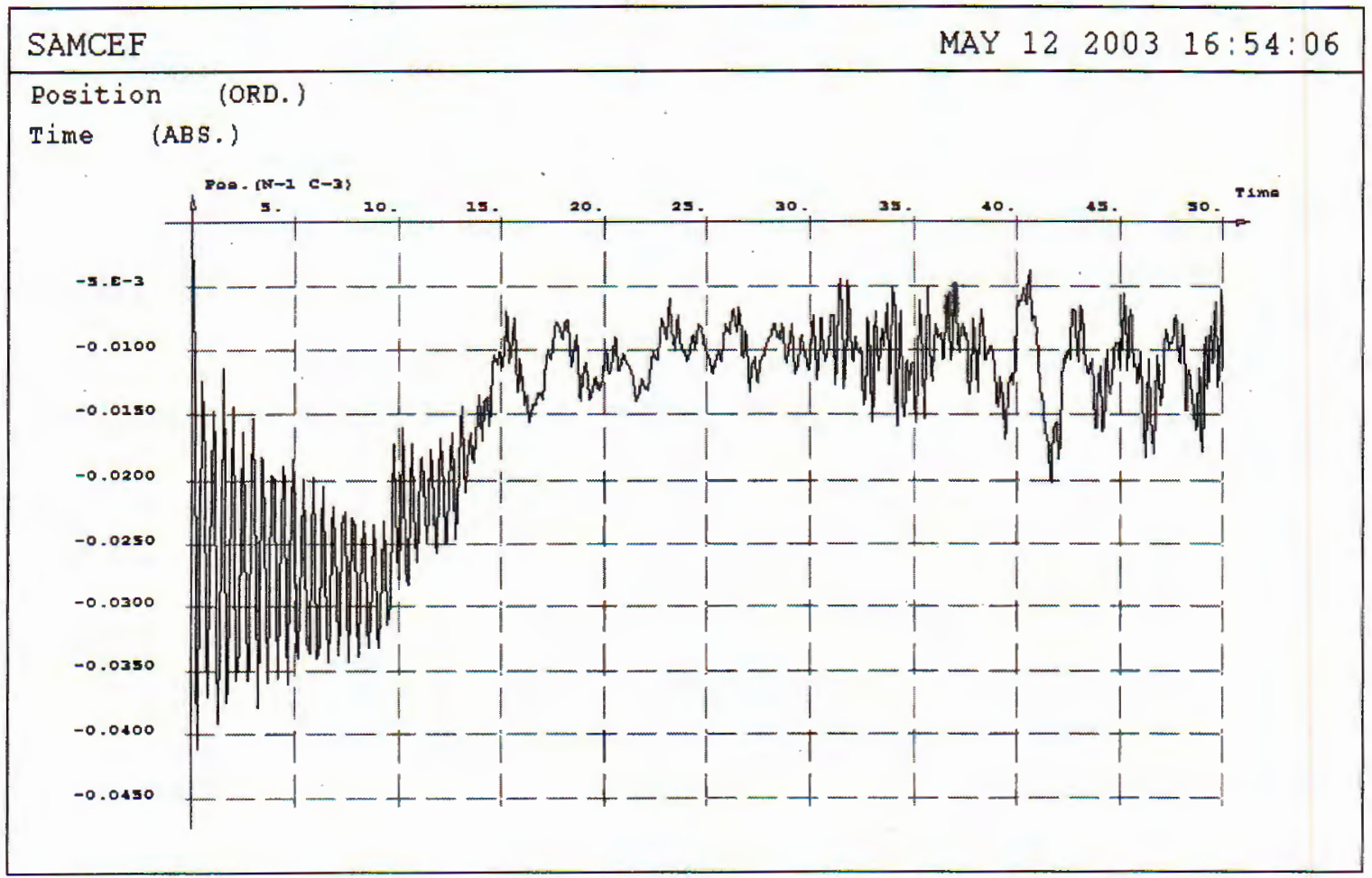

Fig. 5. Displacement of bit

Fig. 6 shows respectively the lateral displacement of node 6. Due to limitation of contact element as showing in Fig. 6, the trajectory of drillstring is very complicated which shows in Fig. 7. There is no doubt that contact behavior cause complex displacement in wellbore. 


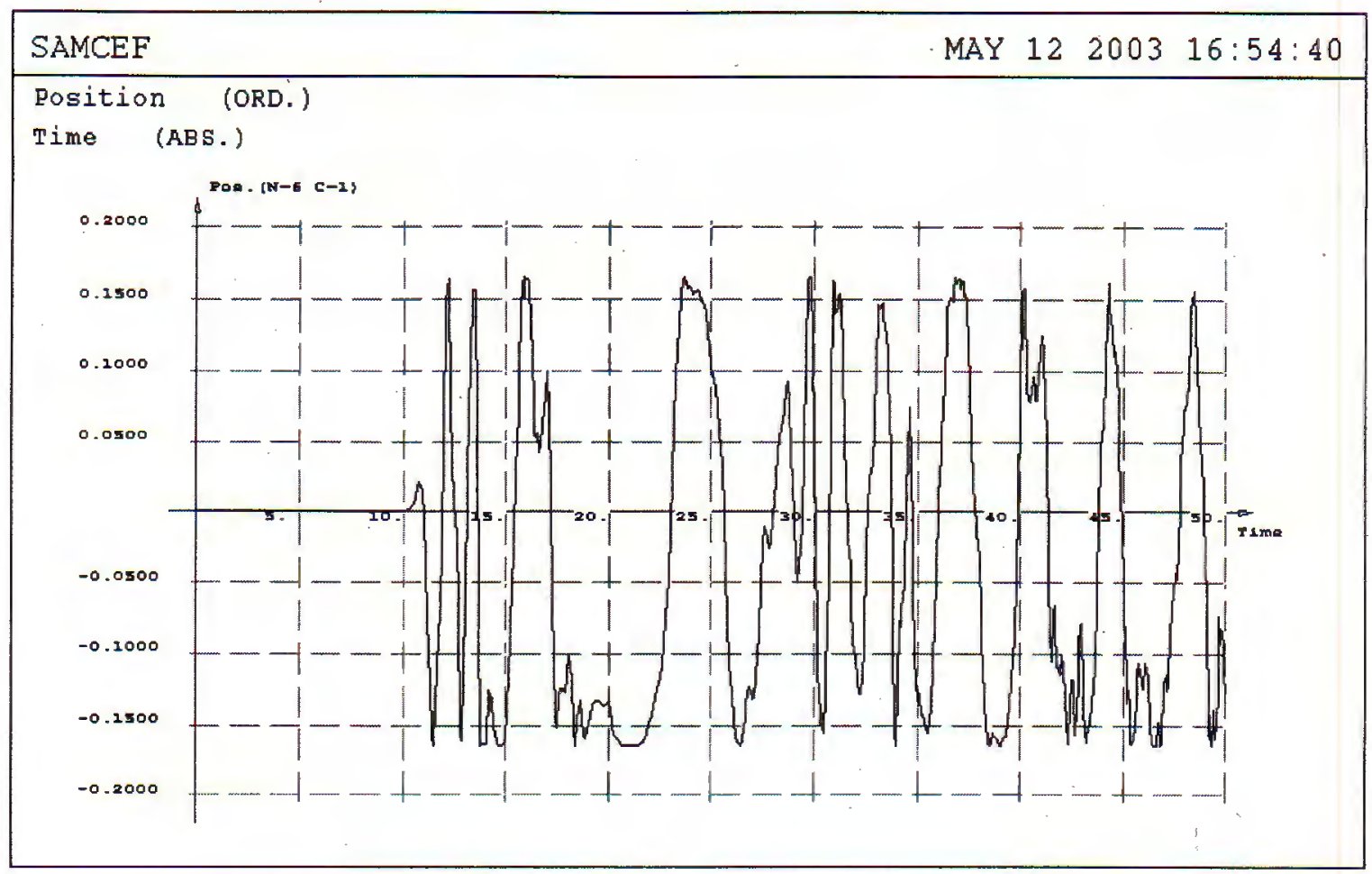

Fig. 6. Displacement at contact point

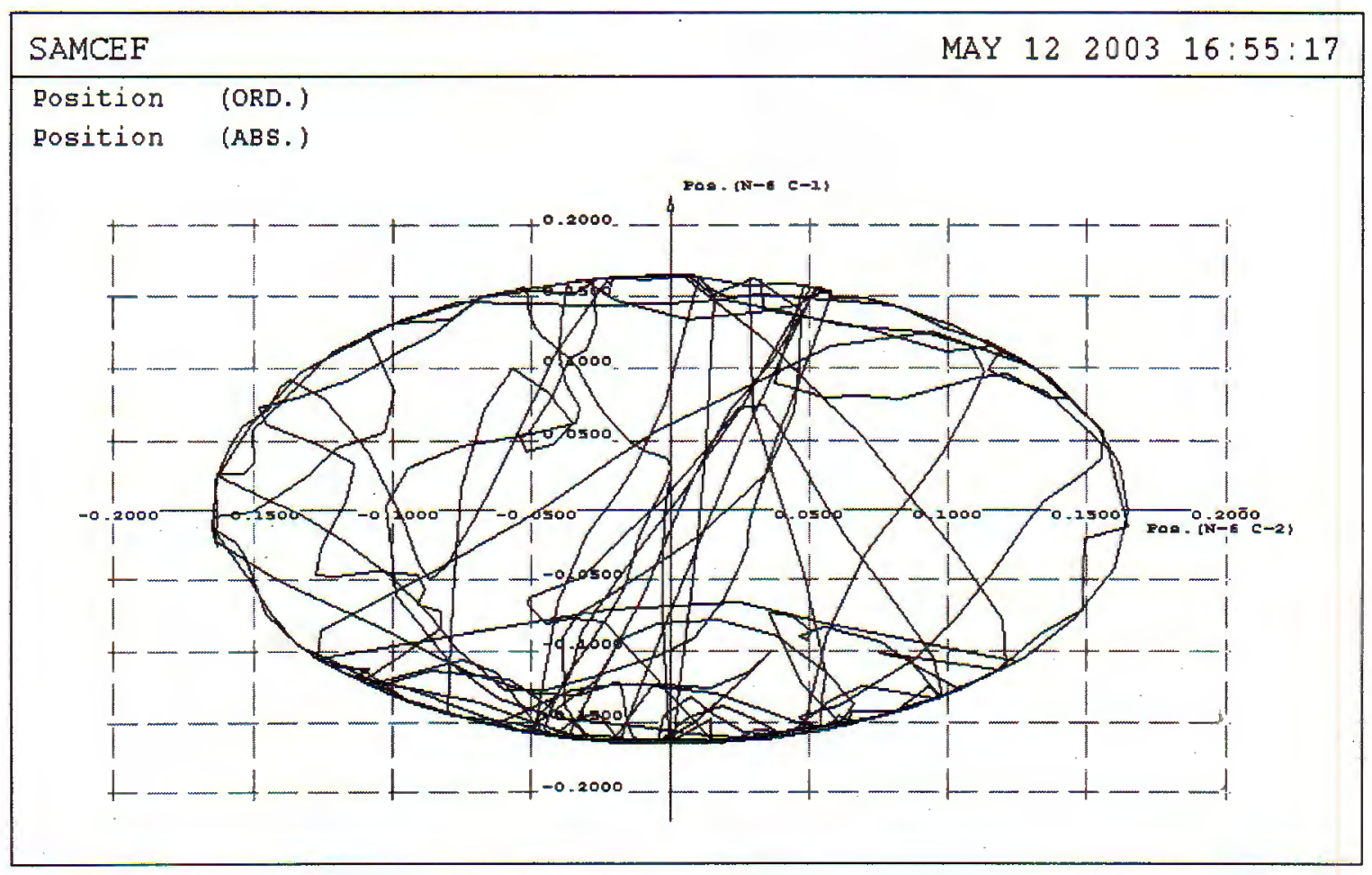

Fig. 7. Trajectory of drillstring 
Fig. 8 presents axial stresses of drillstring versus time. It is clear that stress increases steadily from bit to rotary table. However, the elements which have distance above about $300 \mathrm{~m}$ from the bit is sustained a stress smaller than the elements which is located in neutral distance $(300-500 \mathrm{~m})$. It is similar to the results (table 2) which are calculated by the commercial Drilling Office software of Schlumberger company.

Table 2. Neutral point determination

\begin{tabular}{|c|c|c|c|}
\hline Neutral Point Location & Drilling office & Samcef & $\%$ Error \\
\hline From the Bit $(m)$ & 573.46 & 512 & $10.71 \%$ \\
\hline From the Surface $(\mathrm{m})$ & 3720.87 & 3836 & $10.71 \%$ \\
\hline
\end{tabular}

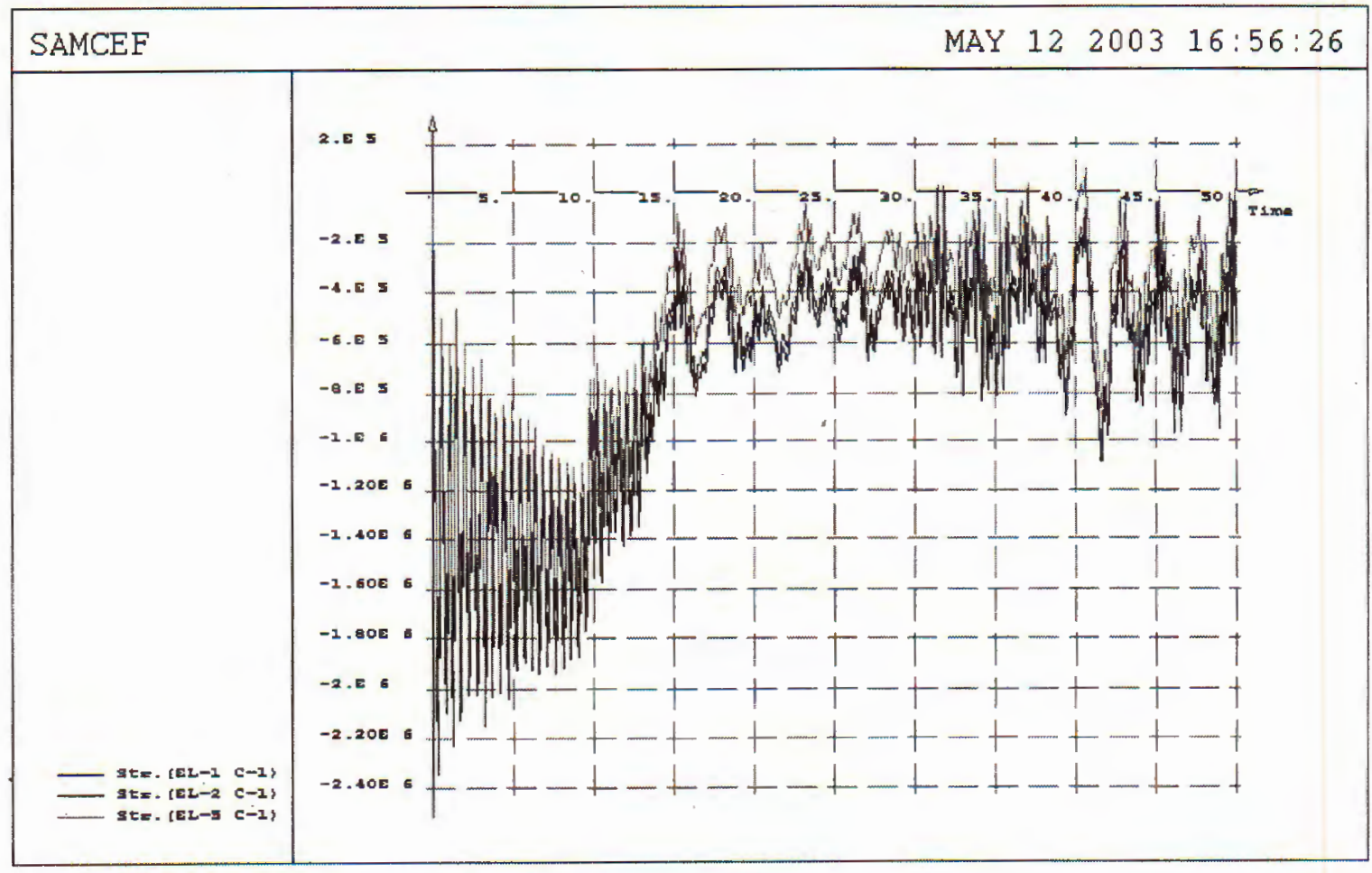

Fig. 8. Axial stress in 1 stabilizer model

\subsubsection{Drillstring model with three stabilizers}

Due to boundary of contact element as showing in figure 9, the trajectory of drillstring is very complicated. Because there are three stabilizers in this model, trajectory of drill string seems simpler than first case. So, that is reason why they usually use more than two stabilizers.

The plot in figure 10 represents the axial stress while rotating drilling with a weight on bit (WOB) of $89 \mathrm{E} 3 \mathrm{~kg}$ in a wellbore versus time. The plot also shows the neutral point (where axial load is zero) around $2000 \mathrm{~m}$. To avoid buckling in these 
sections, the user can reduce the applied WOB, thereby reducing the absolute axial stress. The user can increase the bending stiffness by replacing one or more of the drillstring components (e.g., adding more heavy wall drillpipe HWDP). An effective application of HWDP is a combination of the following methods:

- Replacing drillpipe with HWDP in buckling sections

- Adding HWDP below the buckling sections down to the bit

The side force outputs display the location of significant drillstring/wellbore contact points. The force is normal to the borehole axis and is given as the total force over a specified length of drillstring. This analysis can be used to highlight the location of significant drillstring/wellbore contact points that may lead to longer term well problems, such as key seating and casing wear.

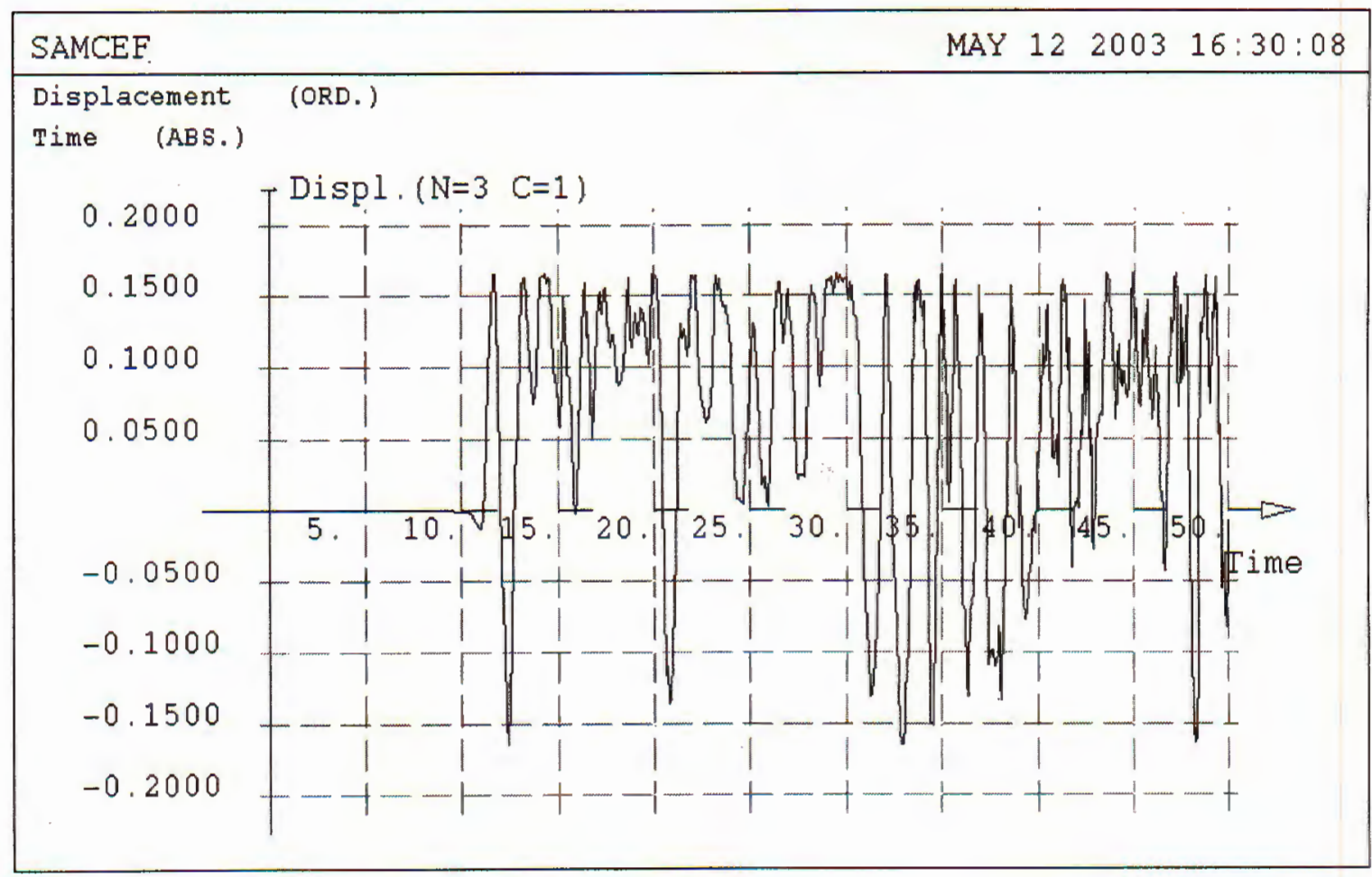

Fig. 9. Lateral position of drillstring at the first stabilizer

Figure 11 shows the side forces for the same drilling parameters for the BHA, wellbore geometry, and survey as the axial load plot (sliding in with a WOB of $83 \mathrm{E} 3 \mathrm{~kg}$ ).

The curve illustrates the magnitude of the side force. For example, the majority of the contact in the lower section of the wellbore is created by the drillstring nearby bit. However, there is significant contact on the top part of the wellbore between $250 \mathrm{~m}$ and $500 \mathrm{~m}$. High side forces can cause problems such as casing wear, key seating, and stuck pipe. The side force magnitude along the drillstring depends heavily upon the well path. A good design of the well path accomplishes the following: 


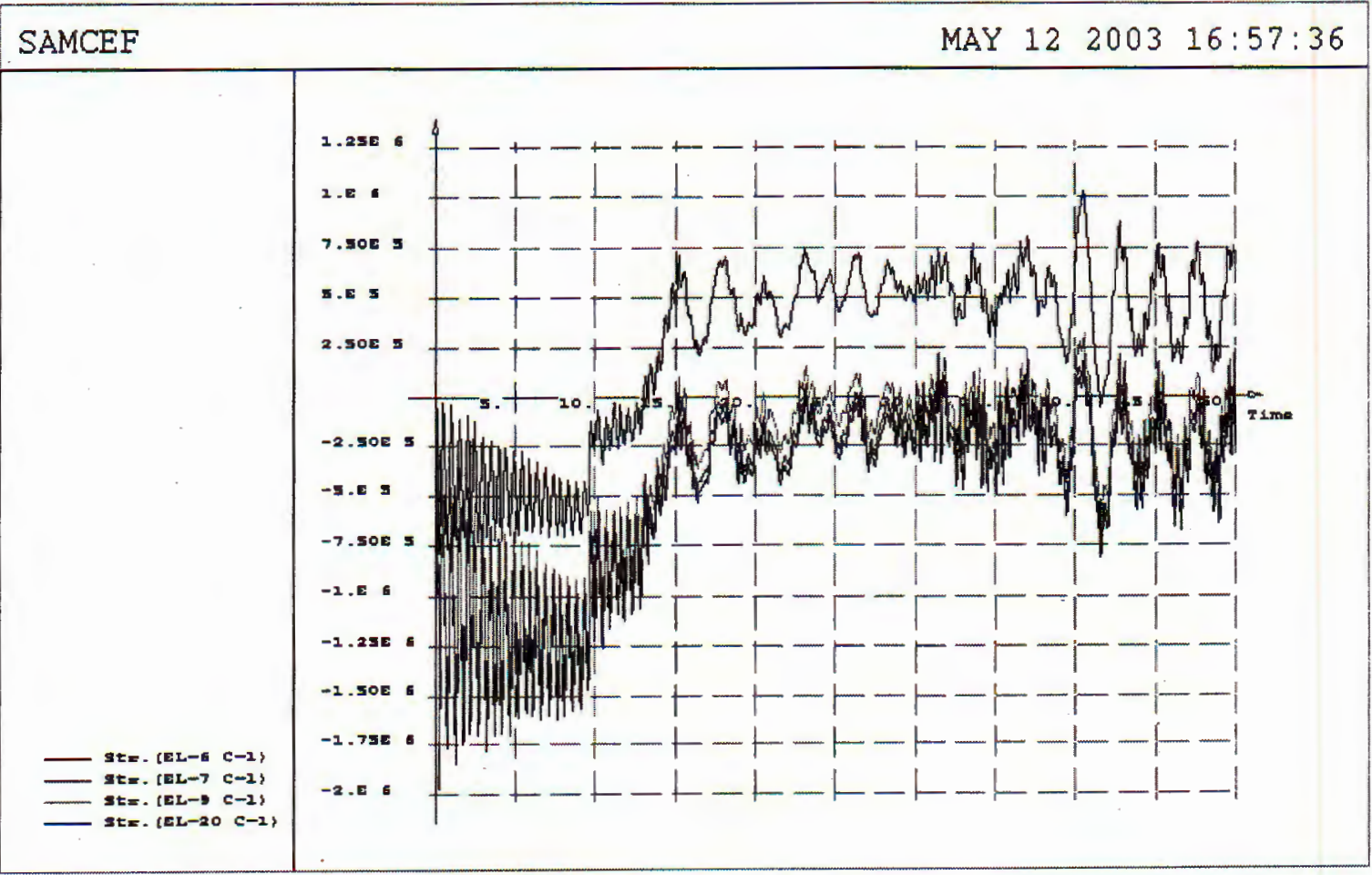

Fig. 10. Axial stress with 3 stabilizer

- Minimizes the side force distribution

- Minimizes the torque profile

- Reduces the difference in the hook load between different drilling operations. (mainly between tripping in and tripping out)

The user can also consider the following objectives for minimizing side force distribution:

- Design well paths with dog leg severity increasing with true vertical depth (TVD) when possible

- Use drill pipe with low linear weight

\section{Conclusions}

- The research of vibration of drillstring is necessary for checking the maximum bending stress against the fatigue limit on each drillstring component and the impact on the overall life of the component.

- Determine position of neutral point. This is very important to estimate length of drill collar.

- It is obvious that using more than 2 stabilizers is better than one because lateral vibration of drillstring will decrease. Consequently, we can control more easily contact forces between the drillstring and the wellbore or casing to identify potential keyseat, casing wear, or stuck pipe areas. 


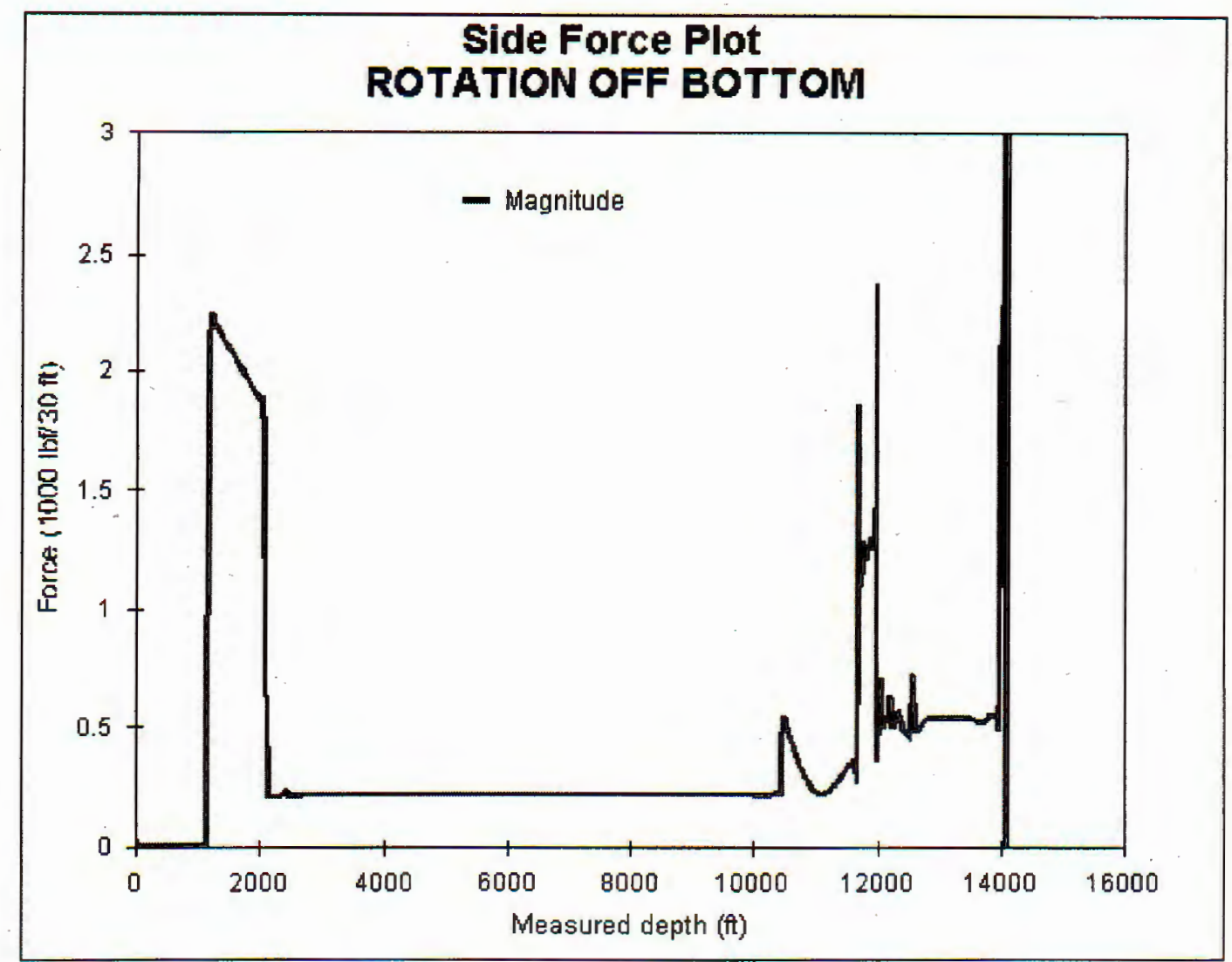

Fig. 11. Contact force calculated by drilling office

- Drill-collar whirling is likely to affect directional drilling. This possibilility requires further research.

- The effects on borehole problems relative to RPM can be dramatic. The RPM must be kept in suitable ranges for the conditions present to drill a wellbore with minimum whole problems.

\section{REFERENCES}

1. Aldred W. D., Sheppard M. C. Drillstring vibrations: a new generation mechanism and control strategies. SPE 24582.

2. Baryshnikov A., Calderoni A., Ligrone A., Ferrara P. A new approach to the analysis of drillstring fatigue behaviour. SPE 30524.

3. Bueno R. C. S., Morooka C.K. Analysis method for contact forces between drillstring-well-riser. SPE 28723

4. Li C. An analytical study of drill string vibrations. SPE 15974. 
5. Geradin M., Rixen D. Mechanical vibrations, theory and application to structural dynamics, second edition, John Wiley \& Son Ltd, 1999.

6. Michel Geradin. Flexible multibody dynamics - a finite element approach, John Wiley \& Son Ltd, 2001.

7. Shilin Chen. Linear and nonlinear dynamics of drillstrings, Liege University, 1996.

8. Ta Quoc Dung. Interaction between drillstring and holewall. Master thesis, the co-program of European Master in Engineering between Liege University and Ho chi Minh City University of Technology, 2003.

Received February 28, 2003

\section{ÚNG DỤNG PHẦN TƯ TIẾP XÚC MÔ PHỎNG TƯONG TÁC CỘT CẦ KHOAN VÀ THÀNH GIẾNG}

Mục đích chính của nghiên cứu là xây dựng phần tử tiếp xúc ứng dụng mô phỏng tiếp xúc giữa bộ khoan cụ và thành giếng. Phần tử tiếp xúc được gắn vào các nút được lựa chọn theo bộ cần khoan. Trong phần tử tiếp xúc lực ma sát vuông góc và lực ma sát tiếp tuyến được tính toán trong đó ma trận giảm chấn và ma trân độ cứng được xét ở dạng tường minh. Các phần từ này được xây dựng trên phần mềm tính toán thương mại Samcef-modul Mecano. Do đó các tính toán của phần mềm Samcef cho dầm phi tuyến, các phương pháp tích phân thời gian sẽ được áp dụng trực tiếp khi thiết lập phần tử tiếp xúc. 